\title{
Peripheral blood lymphocyte apoptosis and its relationship with thyroid function tests in adolescents with hyperthyroidism due to Graves' disease
}

Maria Klatka ${ }^{1}$, Ewelina Grywalska², Agata Surdacka², Jerzy Tarach ${ }^{3}$, Janusz Klatka $a^{4}$, Jacek Roliński

${ }^{1}$ Department of Paediatric Endocrinology and Neurology, Medical University of Lublin, Poland

2Department of Clinical Immunology and Immunotherapy, Medical University of Lublin, Poland

${ }^{3}$ Department of Endocrinology, Medical University of Lublin, Poland

${ }^{4}$ Department of Otolaryngology and Laryngeal Oncology, Medical University of Lublin, Poland

Submitted: 20 March 2011

Accepted: 14 July 2011

Arch Med Sci 2012; 8, 5: 865-873

DOI: $10.5114 /$ aoms.2012.31618

Copyright $\odot 2012$ Termedia \& Banach

\section{Abstract}

Introduction: Failures in apoptotic pathways can contribute to various autoimmune diseases, including autoimmune hyperthyroidism due to Graves' disease (GD). The aim of the present research was to assess changes in the degree of peripheral blood (PB) lymphocyte apoptosis during methimazole (MMI) treatment in the group of teenage children, and to describe its relationship with thyroid function tests.

Material and methods: The percentage of PB apoptotic lymphocytes, assessed by the decrease in mitochondrial transmembrane potential (CMXRos staining), was measured in 30 adolescents at the time of diagnosis and after obtaining normalization of the thyroid hormone levels.

Results: The percentage of apoptotic lymphocytes in previously untreated patients with GD $(5.16 \pm 2.81 \%)$ was significantly lower $(p=0.000001)$ than the percentage of apoptotic cells in the same group of patients after obtaining methimazole-induced euthyroidism $(10.72 \pm 4.66 \%)$. There was a correlation between the increase of the mean percentages of apoptotic lymphocytes and the reduction of FT4 levels $(R=0.63, p<0.0001)$, as well as the reduction of TT3 levels $(R=0.95, p<0.0001)$. The more signs and symptoms accompanying the diagnosis of GD, the higher was the increment of the degree of lymphocyte apoptosis observed during the MMI-treatment $(R=0.74, p<0.0000001)$. The methimazole dosage correlated $(R=0.85, p<0.0001)$ with the percentage of apoptotic cells.

Conclusions: The use of methimazole in treatment of hyperthyroidism due to GD leads to an increment of apoptotic cells in PB. Higher doses of methimazole cause a higher increase of apoptotic lymphocytes. Apoptosis induction of human PB lymphocytes seems to be one of the indicators of proper hyperthyroidism treatment.

Key words: apoptosis, hyperthyroidism, methimazole, mitochondrial transmembrane potential.

\section{Introduction}

Apoptosis, a form of programmed cell death, plays a critical role in the development and homeostasis of tissues, especially those with high

\author{
Corresponding author: \\ Maria Klatka MD, PhD \\ Department of Paediatric \\ Endocrinology and Neurology \\ Medical University of Lublin \\ 7B Szerokie St \\ 20-050 Lublin, Poland \\ Phone: +48 817503109 \\ +48605585376 \\ E-mail: mariaklatka@wp.pl
}


cell turnover such as the lymphoid system [1]. Imbalance between cell death and cell proliferation may cause premature death or uncontrolled cell expansion. Therefore, failures in apoptotic pathways can contribute to various autoimmune diseases [2], including autoimmune hyperthyroidism [3]. Graves' disease (GD) is the most common cause of hyperthyroidism in the paediatric population [4].

The current concept is that thyroid-specific T cells in GD primarily act as helper (CD4+ Th1) cells [5]. When activated, these lymphocytes secrete interleukin-2 (IL-2), interferon $\gamma$, and tumour necrosis factor- $\gamma$, which activate cytotoxic (CD8+) cells and may induce thyroid cell apoptosis. The Th2 lymphocytes secrete IL-4 and IL-5, and activate antibody production. The CD4+ Treg lymphocytes act as anti-inflammatory $T$ cells (CD4+CD25+) and diminish the activity of Th1 and Th2 cells [6]. Moreover, the Th1 and Th2 types of T helper cells interact with each other so that a predominance of Th1 cells does not necessarily mean that the predominant result is apoptosis. T cells may induce target cell death directly, and there is some evidence for a minor degree of thyroid-cell apoptosis in GD [7]. The $T$ cell receptor (TCR) sees antigen in the context of human leukocyte antigen (HLA). This means that the T cell receptor complexes with an HLA molecule on the surface of an antigen-presenting cell: CD8+ cells with HLA class I molecules and CD4+ cells with HLA class II molecules. This complex forms only when the appropriate antigenic peptide is present in the binding pocket of the HLA molecule. Once this complex is formed, the T cell requires an additional stimulus to proliferate and secrete cytokines. This additional stimulus is provided by the same $T$ cell and antigen-presenting cells [8]. If no co-stimulation occurs, the T cell may become anergic or even apoptotic. Thyroid cells express major histocompatibility complex (MHC) molecules in autoimmune thyroid disease and may express co-stimulatory molecules (such as CD40) aiding in intrathyroidal T cell activation. A mechanism which may lead to control of the discussed abnormalities and therefore cure GD is the induction of apoptosis by administering appropriate drugs. Among them, methimazole (MMI) is a drug of choice in the treatment of hyperthyroidism [9].

It is worth noting that autoimmune abnormalities leading to the development of GD can also cause liver and bone marrow dysfunction [10]. As a regulatory mechanism, apoptosis allows the removal of excessive amounts of autoreactive lymphocytes, which may lead to failure of these organs.

Most apoptosis-inducing conditions involve disruption of the mitochondrial inner transmembrane potential $(\Delta \Psi)$, which can be assessed with the use of chloromethyl-X-rosamine (CMXRos) staining. Exploring the phenomenon of induction of lym- phocyte apoptosis during antithyroid therapy is a matter of great importance for understanding the sense of administering antithyroid drugs as the first line of hyperthyroidism treatment. Moreover, MMI-related lymphocyte apoptosis can also affect liver and/or bone marrow function.

The aim of this research was to assess changes in the degree of lymphocyte apoptosis during MMI treatment in a group of teenage children and to describe its relationship with thyroid function tests (TFTs) and complete blood count (CBC).

\section{Material and methods}

\section{Patients}

Between July 2005 and December 2010 peripheral blood (PB) was obtained from 30 previously untreated adolescent patients with hyperthyroidism due to GD (median age: $14.27 \pm 2.13$ years; 24 female, 6 male), hospitalised in the Department of Paediatrics, Division of Paediatric Endocrinology and Neurology in Lublin, Poland. Children with any other health problems or using other medicaments at the time of examination or in the past were excluded from the examined group. The patients were diagnosed on the basis of clinical examination as well as morphological and immunological criteria. In the group of examined children, each presented a wide variety of clinical manifestations of hyperthyroidism at the time of diagnosis [11].

Before antithyroid treatment initiation, blood samples from every child were collected and apoptosis, values of peripheral blood cell count parameters, thyroid-stimulating hormone (TSH), free thyroxine (FT4), and total triiodothyronine (TT3) hormone levels were measured. Using microparticle enzyme immunoassay (Abbott Kit), FT4 and TT3 hormones were assayed. The levels of TSH receptor antibodies (TRAb) were measured by radioimmunoassay (TRAK assay, BRAHMS Diagnostica $\mathrm{GmbH}$, Berlin, Germany). Thyroid peroxidase (TPO) and thyroglobulin (Tg) antibodies were assayed by luminescence immunoassay (Lumitest, BRAHMS Diagnostica $\mathrm{GmbH}$ ). The following reference intervals were determined: TSH 0.49-4.67 $\mathrm{mIU} / \mathrm{l}$, FT4 0.71-1.85 ng/dl, and TT3 0.45-2 ng/ml. Levels of antibodies against TSH receptor less than $1.1 \mathrm{U} / \mathrm{l}$, Tg antibodies less than $35 \mathrm{U} / \mathrm{l}$ and TPO antibodies less than $12 \mathrm{U} / \mathrm{I}$ were considered normal. The patients were treated with methimazole at initial doses of $0.51 \pm 0.05 \mathrm{mg} / \mathrm{kg}$ body weight/day during approximately $27 \pm 10.08$ days, and after that time, when in euthyroidism, blood samples were collected again to assess apoptosis and all the parameters mentioned above. Later the patients received maintenance doses of approximately $0.1 \mathrm{mg} / \mathrm{kg}$ body weight/day (mainly $5 \mathrm{mg} /$ day) $\mathrm{MMI}$ in combination with a low dose of L-thyroxin. The Local 
Ethical Committee approved this study, and informed consent was signed by all the patients.

\section{Cell isolation}

Mononuclear cells were isolated from heparinised peripheral blood samples by density gradient centrifugation on Gradisol-L (Aqua Medica, Poland). Interphase cells were washed twice in phosphate-buffered saline (PBS) and then resuspended at the amount of $0.5-1 \times 10^{6}$ cells.

\section{Flow cytometric analysis}

Analysis of apoptosis within the mononuclear cell population was performed using a Becton Dickinson FACSCalibur flow cytometer (Becton Dickinson, USA), equipped with a 488-nm argon laser. Approximately 10000 events were acquired for each sample. Analysis using CellQuest software was based on gating a subpopulation of lymphoid cells by forward scatter (FSC) versus side scatter (SSC), excluding debris.

\section{Apoptosis}

The percentage of apoptotic lymphocytes was measured at the time of diagnosis, as well as after obtaining normalisation of TSH and thyroid hormones (T4 and T3) levels. Chloromethyl-X-rosamine staining (Mito Tracker Red CMXRos, Molecular Probes, USA) was used to assess apoptosis. CMXRos is a cationic lipophilic fluorochrome that does not accumulate in depolarised mitochondria and that is why it can be used to detect disruptions in mitochondrial membrane potential $\left(\Delta \Psi_{m}\right)$. CMXRos was used in combination with the monoclonal anti-glycophorin A/FITC-conjugated antibody (DAKO, Denmark) to label glycophorin A on the cell surface of erythrocytes. It was considered useful with erythrocyte-contaminated samples with erythrocytes displaying low $\Delta \Psi_{m}$, similarly to apoptotic cells. CMXRos was prepared as a stock solution in dimethylsulfoxide (DMSO) and stored at $-20^{\circ} \mathrm{C}$. The cells were resuspended in $0.5 \mathrm{ml}$ of complete culture medium with $0.2 \mu \mathrm{M} C M X$ Ros working solution and incubated for $30 \mathrm{~min}$ at $37^{\circ} \mathrm{C}$. For the last 15 min of incubation, anti-glycophorin A (FITC) monoclonal antibody was added at the concentration recommended by the manufacturer. The cells were acquired and analysed by the flow cytometer immediately after the incubation period. Cells considered to be apoptotic displayed a decrease in mitochondrial membrane potential in CMXRos staining and were glycophorin A-negative $\left(\Delta \Psi_{m}{ }^{\text {low }} / \mathrm{GlyA}^{-}\right)$.

\section{Statistical analysis}

Student's $t$-test was applied for the statistical comparison of results. The Pearson productmoment correlation coefficient was used as a mea- sure of the linear dependence between variables. The $p$-value $\leq 0.05$ was considered significant. The results are expressed as the median or the mean value \pm standard deviation (SD). Statistica 6.0 PL and Microsoft Excel 2007 software were applied for statistical procedures.

\section{Results}

\section{Patient characteristics}

Patient baseline characteristics are presented in Table I.

Figure 1 presents the flow cytometry dot plots showing the analysis of the ex vivo percentage

Table I. Patient characteristics

\begin{tabular}{|c|c|}
\hline Number of patients & 30 \\
\hline Gender (Female/male) & $24 / 6$ \\
\hline \multicolumn{2}{|l|}{ Age [years]: } \\
\hline Mean \pm SD & $14.27 \pm 2.13$ \\
\hline Median (min.-max.) & $14(11-18)$ \\
\hline \multicolumn{2}{|l|}{ Body weight $[\mathrm{kg}]$ : } \\
\hline Mean \pm SD & $47.30 \pm 10.70$ \\
\hline Median (min.-max.) & $46.75(32-73)$ \\
\hline \multicolumn{2}{|l|}{ Dosage of methimazole [mg/kg/day]: } \\
\hline Mean \pm SD & $0.50 \pm 0.05$ \\
\hline Median (min.-max.) & $0.5(0.42-0.65)$ \\
\hline \multicolumn{2}{|l|}{ Total daily dose of methimazole [mg/day]: } \\
\hline Mean \pm SD & $24 \pm 5.63$ \\
\hline Median (min.-max.) & $22.5(15-40)$ \\
\hline \multicolumn{2}{|l|}{$\begin{array}{l}\text { Treatment duration of hyperthyroidism } \\
\text { (from diagnosis to methimazole-induced } \\
\text { euthyroidism) [days]: }\end{array}$} \\
\hline Mean \pm SD & $27.03 \pm 10.08$ \\
\hline Median (min.-max.) & $25.5(12-53)$ \\
\hline \multicolumn{2}{|l|}{$\begin{array}{l}\text { Symptoms of hyperthyroidism } \\
\text { at the time of diagnosis, } n(\%) \text { : }\end{array}$} \\
\hline Hyperactivity & $30(100)$ \\
\hline Nervousness & $30(100)$ \\
\hline Emotional lability & $28(93.33)$ \\
\hline Weight loss despite excellent appetite & $26(86.67)$ \\
\hline Insomnia & $25(83.33)$ \\
\hline Fatigue & $24(80)$ \\
\hline Palpitations & $24(80)$ \\
\hline Heat intolerance & $20(66.67)$ \\
\hline Sweating & $19(63.33)$ \\
\hline Menstrual irregularities & $7(29.16)$ \\
\hline Muscle weakness & $7(23.33)$ \\
\hline Eye symptoms - pain or diplopia & $5(16.67)$ \\
\hline
\end{tabular}


Table I. Cont.

\begin{tabular}{|c|c|}
\hline $\begin{array}{l}\text { Signs of hyperthyroidism } \\
\text { at the time of diagnosis, } n(\%) \text { : }\end{array}$ & \\
\hline Enlargement of the thyroid gland: & $30(100)$ \\
\hline Goitre class I & $12(40)$ \\
\hline Goitre class II & $13(43.33)$ \\
\hline Goitre class III & $5(16.67)$ \\
\hline Tachycardia & $30(100)$ \\
\hline Smooth sweaty skin & $25(83.33)$ \\
\hline Tremor or muscle fasciculations & $24(80)$ \\
\hline Eye findings: & $20(66.67)$ \\
\hline Exophthalmos (proptosis) & $8(26.67)$ \\
\hline Lid retraction & $6(20)$ \\
\hline Conjunctival injection & $6(20)$ \\
\hline Exaggerated deep-tendon reflexes & $20(66.67)$ \\
\hline Wide pulse pressure & $18(60)$ \\
\hline Hypertension & $6(20)$ \\
\hline \multicolumn{2}{|l|}{ Antithyroid antibodies } \\
\hline $\begin{array}{l}\text { TRAb-positive patients, } n(\%) \\
\text { level of antibodies against TSH receptor } \\
\text { more than } 1.1 \mathrm{U} / l\end{array}$ & $30(100)$ \\
\hline $\begin{array}{l}\text { AntiTPO-positive patients, } n(\%) \\
\text { level of antibodies against TPO } \\
\text { more than } 12 \mathrm{U} / l\end{array}$ & $21(70)$ \\
\hline $\begin{array}{l}\text { AntiTg-positive patients, } n(\%) \\
\text { level of antibodies against } \mathrm{Tg} \\
\text { more than } 35 \mathrm{U} / \mathrm{l}\end{array}$ & $7(23.33)$ \\
\hline
\end{tabular}

of apoptotic cells - data from a single patient with hyperthyroidism before the treatment (I) and after normalisation of the thyroid function test parameters (II). The analysis was based on gating a subpopulation of lymphoid cells by forward scatter (FSC) versus side scatter (SSC) (A). Then the gated events were analysed for CMXRos (B), which was used to detect disruptions in mitochondrial membrane potential $\left(\Delta \Psi_{\mathrm{m}}\right)$, and the monoclonal antiglycophorin A/FITC-conjugated antibody - to label glycophorin A on the cell surface of erythrocytes. Cells considered to be apoptotic displayed a decrease in mitochondrial membrane potential in CMXRos staining and were glycophorin A-negative $\left(\Delta \Psi_{\mathrm{m}}{ }^{\text {low }} / \mathrm{GlyA}^{-}\right)-$a lower left quadrant of each dot plot (B I, $R^{2}=1.8 \%$; $\left.\mathrm{II}, R^{2}=19.2 \%\right)$.

Assessment of the percentage of apoptotic cells in previously untreated patients with hyperthyroidism due to Graves' disease by CMXRos staining

It was found that the ex vivo percentage of peripheral blood apoptotic $\left(\Delta \Psi_{m}\right.$ low/Gly-A $\left.{ }^{-}\right)$cells
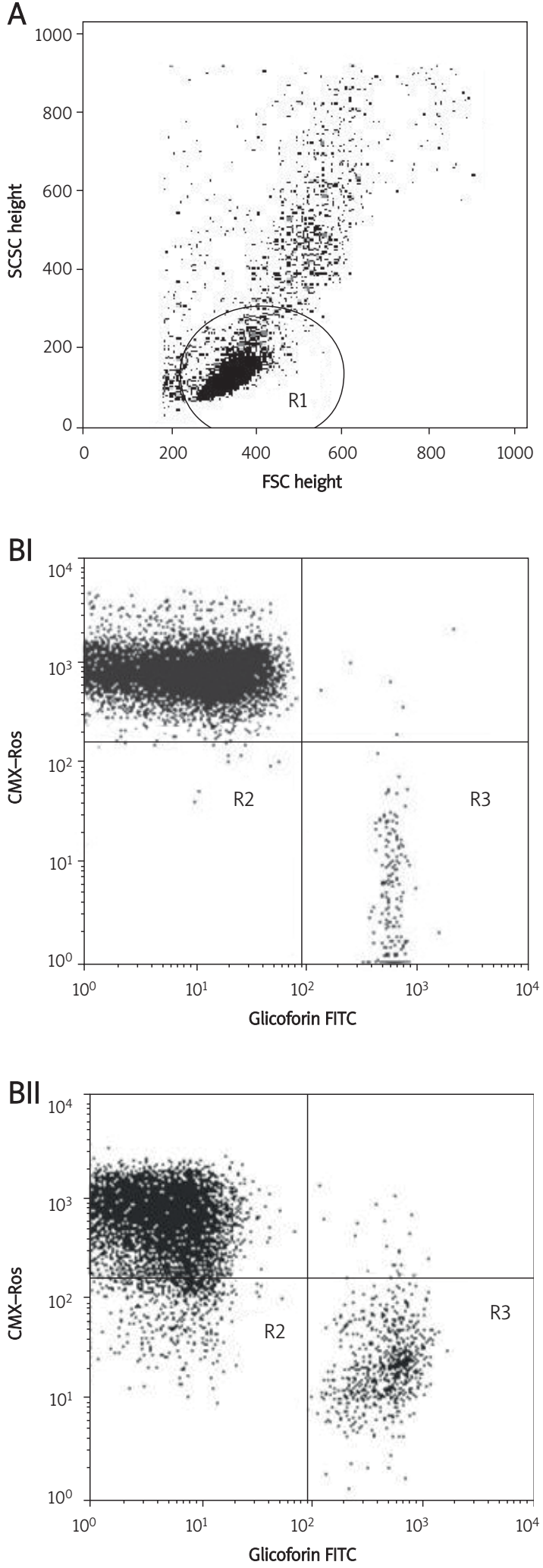

Figure 1. Flow cytometry dot plots showing the analysis of the ex vivo percentage of apoptotic cells - data from a single patient with hyperthyroidism before the treatment $\left(\mathrm{BI}, R^{2}=1.8 \%\right)$ and after the normalisation of thyroid function test parameters (BII, $R^{2}=$ $19.2 \%)$. A - gating a subpopulation of lymphoid cells by forward scatter (FSC) vs. side scatter (SSC) 


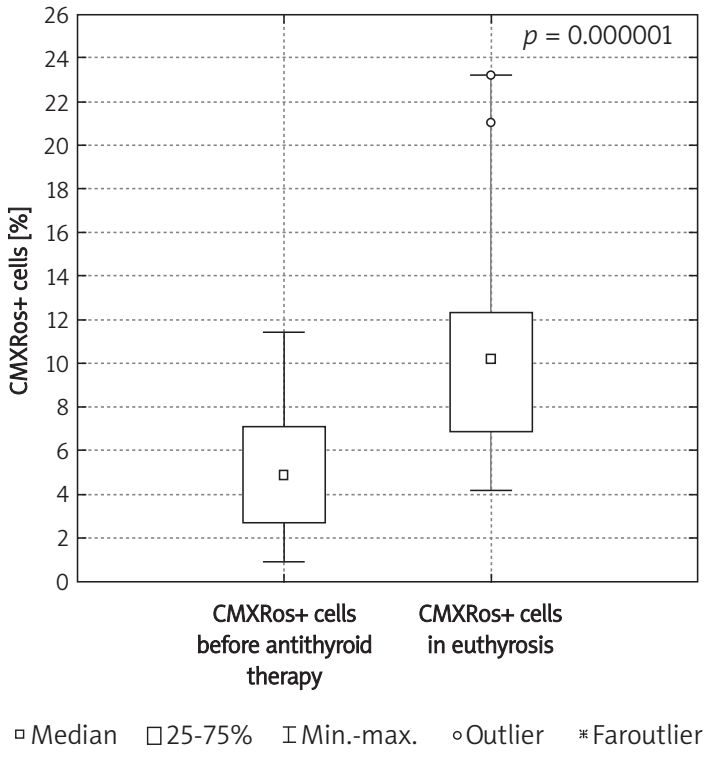

Figure 2. Ex vivo percentage of apoptotic cells evaluated by CMXRos in previously untreated patients with hyperthyroidism due to GD and in euthyroidism, induced by methimazole treatment

in previously untreated patients with hyperthyroidism due to GD (mean: $5.16 \pm 2.81 \%$, median: $4.85 \%)$ was significantly lower $(p=0.000001)$ than the percentage of $\Delta \Psi_{m}{ }^{\text {low } / G l y-A^{-}}$apoptotic cells in the same group of patients after receiving approximately $0.5 \mathrm{mg} / \mathrm{kg}$ body weight per day of $\mathrm{MMI}$ (mean: $10.72 \pm 4.66 \%$, median: $10.15 \%$ ). The $a b-$ solute count of apoptotic lymphocytes amounted to $87.92 \pm 59.90 / \mathrm{mm}^{3}$ before the treatment initiation and $173.39 \pm 93.63 / \mathrm{mm}^{3}$ after obtaining normalisation of TFT parameters (Figure 2).

\section{The relationship between the percentage of apoptotic cells and TFTs (FT4, TT3 and TSH hormone levels)}

In the group of patients before treatment, the mean value of FT4 hormone level was 3.64 $\pm 1.40 \mathrm{ng} / \mathrm{dl}$, median $3.46 \mathrm{ng} / \mathrm{dl}$, and in children after normalisation of TFT parameters it was $1.21 \pm 0.29$ $\mathrm{ng} / \mathrm{dl}$, median $1.16 \mathrm{ng} / \mathrm{dl}(p<0.0001)$. Similarly, in patients before treatment, the mean value of TT3 hormone level was $3.29 \pm 1.25 \mathrm{ng} / \mathrm{ml}$, median 2.98 $\mathrm{ng} / \mathrm{ml}$, and in children after treatment it was 1.27 $\pm 0.28 \mathrm{ng} / \mathrm{ml}$, median $1.28 \mathrm{ng} / \mathrm{ml}(p<0.0001)$. Before the therapy the TSH level was $0.09 \pm 0.12 \mu \mathrm{lU} / \mathrm{ml}$, median $0.03 \mu \mathrm{lU} / \mathrm{ml}$, and after methimazole treatment in the initial dose the TSH level was $1.31 \pm 0.95$ $\mu \mathrm{lU} / \mathrm{ml}$, median $0.8 \mu \mathrm{lU} / \mathrm{ml}(p<0.0001)$. The diagram showing the relation between FT4 and TT3 hormone levels and the percentage of apoptotic cells in previously untreated patients with hyperthyroidism due to GD is presented in Figure 3. The present study indicates that there is a correla-

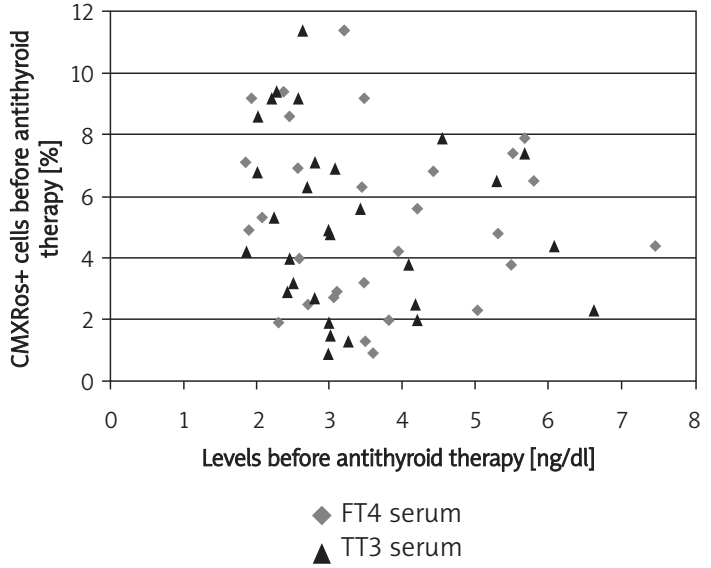

Figure 3. Diagram showing the relation between FT4 and TT3 hormone levels and the percentage of apoptotic cells in previously untreated patients with hyperthyroidism due to Graves' disease

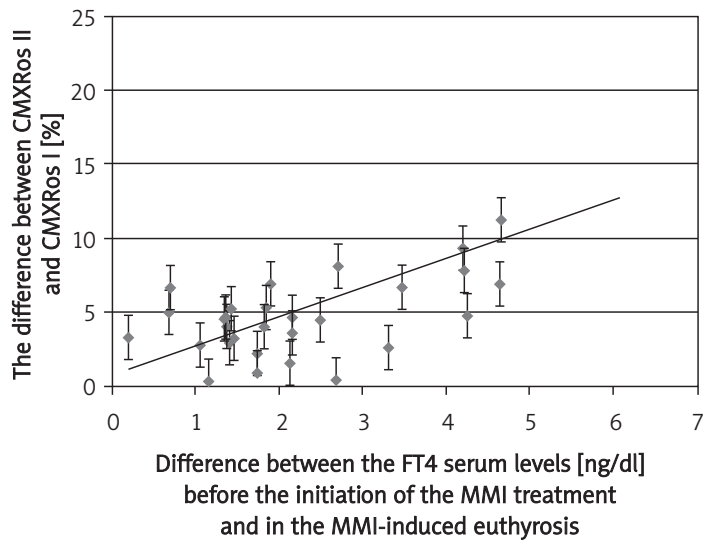

Figure 4. Percentages of $\Delta \Psi_{m}^{\text {low }} / \mathrm{Gly}-\mathrm{A}^{-}$apoptotic cells measured by the difference between the percentages of CMXRos+ cells (CMXRos II) after the normalisation of TFTs and CMXRos+ cells (CMXRos I) before treatment in relation to the reduction of FT4 levels (ng/dl)

tion between the increase of the mean percentage of apoptotic cells assessed by CMXRos staining and the reduction of FT4 levels $(R=0.63, p<0.0001)$ (Figure 4) as well as the reduction of TT3 levels $(R=0.95, p<0.0001)$ (Figure 5$)$. No relation between the percentage of apoptotic cells and TSH levels was observed.

\section{The relation between the percentages of $\Delta \Psi_{m}$ low/Gly-A $A^{-}$apoptotic cells and clinical features of hyperthyroidism}

To perform this analysis, the present authors considered ten of the most common symptoms (hyperactivity, nervousness, emotional lability, weight loss despite excellent appetite, insomnia) and signs (enlargement of the thyroid gland, tachycardia, smooth sweaty skin, tremor or muscle fasciculations, eye findings) of hyperthyroidism [11] and the differ- 


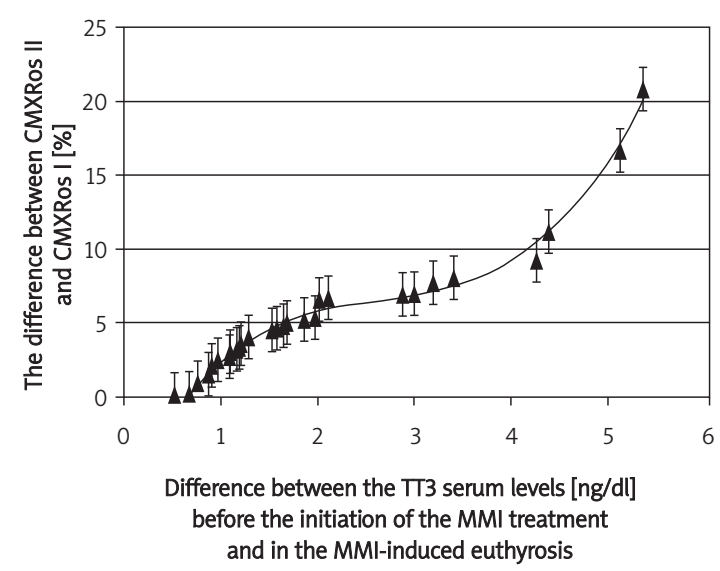

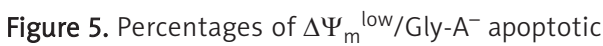
cells measured by the difference between the percentages of CMXRos+ cells (CMXRos II) after the normalisation of TFTs and CMXRos+ cells (CMXRos I) before treatment in relation to the reduction of TT3 levels (ng/ml)

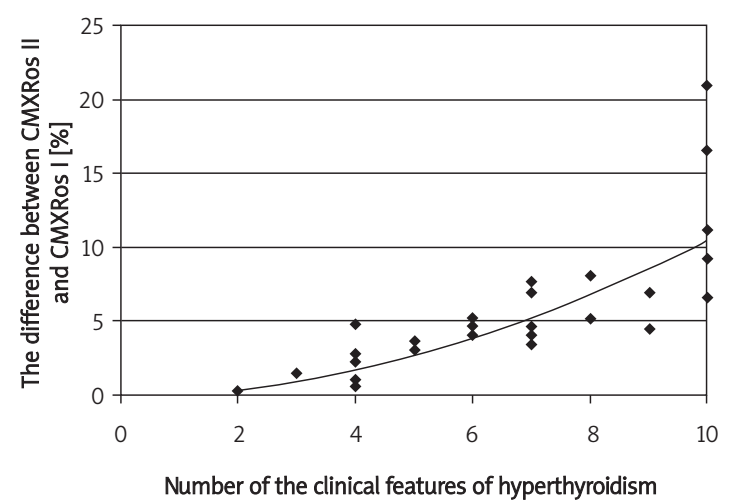

Figure 6. Percentages of $\Delta \Psi_{m}$ low/Gly- $\mathrm{A}^{-}$apoptotic cells measured by the difference between the percentages of CMXRos+ cells (CMXRos II) after the normalisation of TFTs and CMXRos+ cells (CMXRos I) before treatment in relation to the clinical features of hyperthyroidism

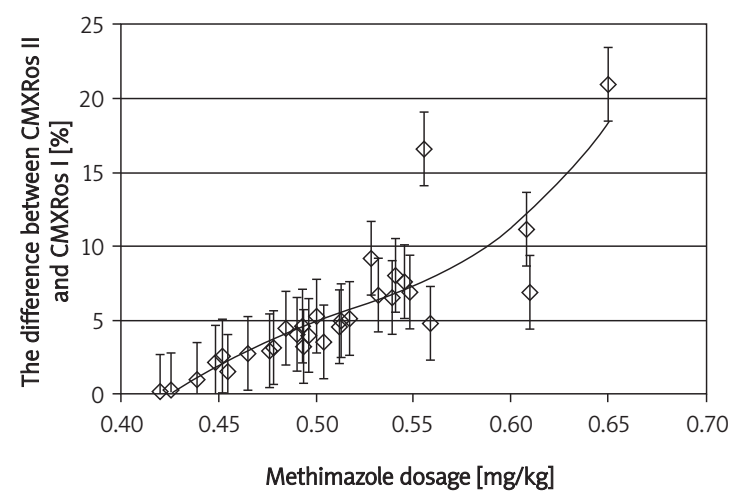

Figure 7. Percentages of $\Delta \Psi_{m}^{\text {low }} / G$ ly- $A^{-}$apoptotic cells measured by the difference between the percentages of CMXRos+ cells (CMXRos II) after the normalisation of TFTs and CMXRos+ cells (CMXRos I) before treatment in relation to the methimazole dosage ence between the percentages of CMXRos+ cells after the normalisation of TFTs and CMXRos+ cells before treatment. It was found that the more signs and symptoms there were accompanying the diagnosis of GD, the higher was the degree of lymphocyte apoptosis observed during $\mathrm{MMI}$ treatment $(R=0.74, p<0.0000001$, Figure 6).

\section{The relation between the percentages of $\Delta \Psi_{m}$ low/Gly-A- apoptotic cells and methimazole dosage}

In the present study, the authors observed that the methimazole dosage had a strongly positive correlation $(R=0.85, p<0.0001)$ with the percentages of $\Delta \Psi_{m}$ low/Gly-A- apoptotic cells measured by the difference between the percentages of CMXRos+ cells after the normalisation of TFTs and CMXRos+ cells before treatment (Figure 7).

\section{The assessment of haematological findings in children with hyperthyroidism before MMI treatment and in MMl-induced euthyroidism}

The most interesting haematological findings concerned white blood cells. The present study revealed that there was a negative correlation between treatment duration and mean percentage of basophils $(R=-0.42, p<0.05)$ as well as mean percentage of lymphocytes $(R=-0.49, p<0.01)$, and a positive correlation with mean percentage of neutrophils $(R=0.63, p<0.0001)$. The study also revealed that an increment of CMXRos+ cells positively correlated with the percentage of monocytes $(R=0.48, p<0.01)$. Figure 8 presents the percentage (I) and the absolute value (II) of white blood cells and the five basic cell types (NEU - neutrophils, LYM - lymphocytes, MON - monocytes, EOS eosinophils and BAS - basophils) before MMI treatment and in MMI-induced euthyroidism.

\section{Discussion}

One of the most important findings of the studies on autoimmune diseases' biology is the discovery that apoptosis plays an essential role in the pathogenesis of several disorders belonging to this group. The latest results from the study of Kaczmarek et al. [12] indicated that apoptosis plays a major role in the pathogenesis of autoimmune thyroid diseases. Nevertheless, none of the authors tried to assess one of the earliest markers of apoptosis, which is the loss of mitochondrial transmembrane potential in the group of GD patients. For detection of apoptotic lymphocytes in the circulation, inner mitochondrial transmembrane potential was measured using chloromethyl-Xrosamine (CMXRos) and flow cytometry [13-16].

Autoimmune diseases are characterized by the activity of autoreactive lymphocytes that pro- 
A

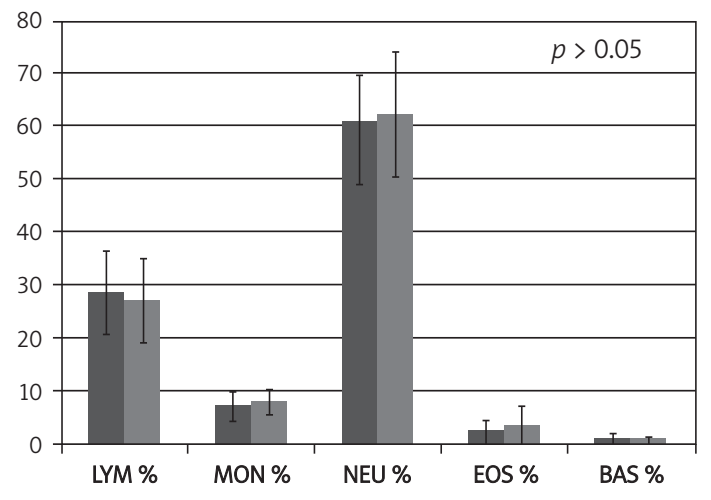

B

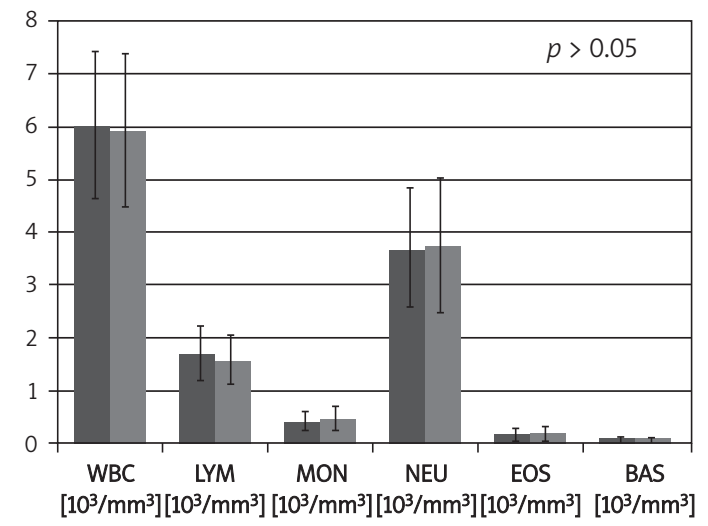

White blood cells assessment before the MMI treatment

White blood cells assessment in MMI-induced euthyrosis

Figure 8. Percentage $(\mathbf{A})$ and absolute value $(B)$ of white blood cells and the five basic cell types before MMI treatment and in MMl-induced euthyroidism

duce antibodies targeting self tissue or organs for destruction [17]. The course of GD is associated with the inflow of lymphocytes to the thyroid gland and dysregulation of the immune system characterized by reaction to thyroid antigens (peroxidase, thyroglobulin, TSH receptors and $\mathrm{Na}+/ \mathrm{I}$ - symporter). After activation they shift to the inflamed thyroid gland, thus leading to the production of cytokines which can stimulate activity of thyrocytes and increase expression of intracellular proapoptotic markers such as TIAR and TIA-1 [18]. Other authors emphasize that in GD, the Th2 cytokine profile is associated with upregulation of antiapoptotic molecules, rendering the thyrocytes but not the infiltrating lymphocytes immune from apoptosis [19]. The percentage of apoptotic thyrocytes in situ is decreased in GD, suggesting the importance of apoptotic cell death of thyrocytes in the regulation of functions and numbers of the discussed cells in this autoimmune thyroid disease [20].

The present authors hypothesized that evaluation of ex vivo apoptosis before and during the therapy of hyperthyroidism due to GD might provide new important information concerning its biology and treatment. In the discussed study, CMXRos technique was used as the method of early apoptosis evaluation. CMXRos is a fluorochrome that can be used to detect disruptions in mitochondrial membrane potential $\left(\Delta \Psi_{\mathrm{m}}\right)$, one of the earliest events in the apoptotic pathway [21, 22].

The results of this research have indicated that the spontaneous apoptosis in GD patients before treatment was significantly lower compared to the same group of children with methimazoleinduced euthyroidism. Our study revealed that the normalization of thyroid hormones increases lymphocyte apoptosis. What is more, ex vivo spontaneous apoptosis was higher in patients present- ing a wide variety of the signs and symptoms of hyperthyroidism. Moreover, the dose of $\mathrm{MMI}$ strongly positively correlated with the percentage of apoptosis.

The results of the performed studies are surprising, as Mihara et al. [1] found that T lymphocytes cultured with T3 and T4 in vitro showed enhanced apoptosis, evidenced by DNA ladder formation and characteristic morphological changes. In addition, prolonged cultivation with thyroid hormones of the lymphocytes further enhanced the extent of apoptosis. Furthermore, the treatment with thyroid hormones of $\mathrm{T}$ lymphocytes induced reduction of mitochondrial transmembrane potential and production of reactive oxygen species, both of which are intimately associated with apoptotic cell death. These findings suggest that thyroid hormones have the potential to induce apoptotic cell death of human lymphocytes in vitro. The results of the present study seem to reveal that thyroid hormones also exert a negative or even no influence on cellular apoptosis ex vivo, as the treatment of hyperthyroidism in all patients leads to the increment of apoptotic cells. Other authors showed that thyroid hormones inhibit apoptosis of early differentiating cerebellar granule neurons through an increase in the amounts of $\mathrm{Bcl}-2$ protein [23]. Thus, increased serum Bcl-2 may be linked to accelerated apoptosis. In euthyroid Hashimoto's thyroiditis patients compared with controls and euthyroid GD, increased serum Bcl-2 has been reported [24]. In the study of Jiskra et al. [25], a tendency towards higher Bcl-2 in Hashimoto's thyroiditis patients was found, with no difference in serum $\mathrm{BCl}-2$ between hyperthyroid GD and when the euthyroid state was achieved.

The MMI (or carbimazole) should be considered the drug of choice for GD. The typical MMI dose is 
0.2-0.5 $\mathrm{mg} / \mathrm{kg}$ per day, with a range from 0.1 to $1.0 \mathrm{mg} / \mathrm{kg}$ per day [26]. The MMI reduces thyroid hormone synthesis by inhibiting the oxidation and organic binding of thyroid iodide. It is 10 - to 20 -fold more potent than other antithyroid drugs and has a longer half-life [27, 28]. Thionamides also lower the levels of thyroid autoantibodies, sometimes leading to long-term remission [29-31]. Fas ligand (FasL) induces apoptosis of susceptible cells by cross-linking its own receptor, Fas. While Fas is present in a wide variety of normal tissues, FasL expression is limited mainly to cells of the immune system, where it acts as an effector molecule of cell-mediated cytotoxicity, and eliminates infiltrating lymphocytes in immune-privileged organs. FasL expression is very weak in cultured thyrocytes, whereas it is strong in thionamide-treated GD glands and cultured thyrocytes. Methimazole-treated thyrocytes induce FasL-dependent apoptosis in co-cultured lymphocytes [32]. Therefore, the results of our studies, showing a positive linear correlation between MMI dosage and the increment of apoptotic cells, confirm that this drug is able to induce lymphocyte apoptosis. The MMI seems to act not only by the Fas-FasL pathway [32, 33] but also by interaction with the mitochondrial membrane and may contribute to the immunomodulatory effect of thionamides in this disease.

The MMI-related adverse effects include agranulocytosis and allergic reactions. Agranulocytosis has been reported in about $0.3 \%$ of adult patients taking MMI [34, 35] and is dose-dependent with $\mathrm{MMI}$; therefore it rarely occurs at low doses [34, 35]. When it develops, agranulocytosis occurs over the first 100 days of therapy in $95 \%$ of individuals $[34,35]$. We observed that WBC and lymphocytes were slightly diminished in the course of MMI treatment, but this finding can be connected with the anti-inflammatory effect of this drug, because other studies suggest that methimazole may also decrease pathological inflammation [36, 37]. Methimazole can reduce TNF- $\alpha$-induced VCAM- 1 expression in an IFN regulatory factor-1-dependent manner and that significantly contributes to reduced monocytic cell adhesion [38]. The present research has also revealed that treatment with $\mathrm{MMI}$ leads to an increase of the percentages of monocytes as well as the absolute count of these cells and the discussed parameters positively correlate with the percentages of apoptotic lymphocytes. The discussed study found a negative correlation between the treatment duration and mean percentage of basophils, but the role of this finding remains unclear.

In order to clarify the lymphocyte apoptosis issue in the therapy of GD with MMI, further studies are needed to identify the critical apoptosis-inducing molecules whose expression/function is modulat- ed by the thyroid hormone as well as methimazole treatment.

In conclusion, the use of methimazole in treatment of hyperthyroidism due to GD leads to an increment of apoptotic cells in peripheral blood. Higher doses of methimazole cause a higher increase of apoptotic lymphocytes in peripheral blood. Higher activity of the disease, assessed by the presented signs and symptoms, is connected with better reaction to the treatment measured by the increase of the percentage of apoptotic cells. Apoptosis induction of human peripheral blood lymphocytes seems to be one of the indicators of proper hyperthyroidism treatment.

\section{References}

1. Mihara S, Suzuki N, Wakisaka S, et al. Effects of thyroid hormones on apoptotic cell death of human lymphocytes. J Clin Endocrinol Metab 1999; 84: 1378-85.

2. Fooladi AA, Sattari M, Nourani MR. Study of T-cell stimulation and cytokine release induced by Staphylococcal enterotoxin type B and monophosphoryl lipid A. Arch Med Sci 2009; 5: 335-41.

3. Wang SH, Baker JR. The role of apoptosis in thyroid autoimmunity. Thyroid 2007; 17: 975-9.

4. Rivkees SA. The treatment of Graves' disease in children. J Pediatr Endocrinol Metab 2006; 19: 1095-111.

5. Liblau RS, Singer SM, McDevitt HO. Th1 and Th2 CD4+ $T$ cells in the pathogenesis of organ-specific autoimmune diseases. Immunol Today 1995; 16: 34.

6. Mills KH. Regulatory T cells: friend or foe in immunity to infection? Nat Rev Immunol 2004; 4: 841.

7. Stassi G, Di Liberto D, Todaro M, et al. Control of target cell survival in thyroid autoimmunity by $T$ helper cytokines via regulation of apoptotic proteins. Nat Immunol 2000; 1: 483.

8. Abbas AK, Murphy KM, Sher A. Functional diversity of helper T lymphocytes. Nature 1996; 383: 787.

9. Cooper DS. Antithyroid drugs. N Engl J Med 2005; 352: 905-17.

10. Karras S, Tzotzas T, Krassas GE. Toxicological considerations for antithyroid drugs in children. Expert Opin Drug Metab Toxicol 2011; 7: 399-410.

11. Oszukowska L, Knapska-Kucharska M, Lewiński A. Effects of drugs on the efficacy of radioiodine (1311) therapy in hyperthyroid patients. Arch Med Sci 2010; 6: 4-10.

12. Kaczmarek E, Lacka K, Jarmolowska-Jurczyszyn D, Sidor A, Majewski P. Changes of B and T lymphocytes and selected apopotosis markers in Hashimoto's thyroiditis. J Clin Pathol 2011 (published online).

13. Korycińska A, Dabrowski W, Rzecki Z, et al. The degree of lymphocytic mitochondrial transmembrane potential and blood magnesium concentrations during coronary artery bypass grafting. Magnes Res 2005; 18: 253-60.

14. Macho A, Decaudin D, Castedo M, et al. Chloromethyl-Xrosamine - a fluorochrome for the determination of the mitochondrial transmembrane potential. Cytometry 1998; 31: 75.

15. Poot M, Pierce RC. Detection of apoptosis and changes in mitochondrial membrane potential with chloromethyl-Xrosamine. Cytometry 1999; 36: 359-60.

16. Pendergrass W, Wolf N, Poot M. Efficacy of MitoTracker Green $^{\mathrm{TM}}$ and CMXRosamine to measure changes in 
mitochondrial membrane potentials in living cells and tissues. Cytometry 2004; 61: 162-9.

17. Todaro M, Zeuner A, Stassi G. Role of apoptosis in autoimmunity. J Clin Immunol 2004; 24: 1-11.

18. Bossowski A, Czarnocka B, Bardadin K, et al. Identification of chosen apoptotic (TIAR and TIA-1) markers expression in thyroid tissues from adolescents with immune and nonimmune thyroid diseases. Folia Histochem Cytobiol 2010; 48: 178-84.

19. Brown RS. Autoimmune thyroid disease: unlocking a complex puzzle. Curr Opin Pediatr 2009; 21: 523-8.

20. Ai J, Leonhardt JM, Heymann WR. Autoimmune thyroid diseases: etiology, pathogenesis, and dermatologic manifestations. J Am Acad Dermatol 2003; 48: 641-59.

21. Minamikawa T, Sriratana A, Williams DA, Bowser DN, Hill JS, Nagley P. Chloromethyl-X-rosamine (MitoTracker Red) photosensitises mitochondria and induces apoptosis in intact human cells. J Cell Sci 1999; 112: 2419-30.

22. Jayaraman S. Flow cytometric determination of mitochondrial membrane potential changes during apoptosis of T lymphocytic and pancreatic beta cell lines: comparison of tetramethylrhodamineethylester (TMRE), chloromethyl-X-rosamine (H2-CMX-Ros) and MitoTracker Red 580 (MTR580). J Immunol Methods 2005; 306: 68-79.

23. Muller Y, Rocchi E, Lazaro JB, Clos J. Thyroid hormone promotes $\mathrm{Bcl}-2$ expression and prevents apoptosis of early differentiating cerebellar granule neurons. Int I Dev Neurosci 1995; 13: 871-85.

24. Myśliwiec J, Okota M, Nikołajuk A, Górska M. Soluble Fas, Fas ligand and $\mathrm{BCl}-2$ in autoimmune thyroid diseases: relation to humoral immune response markers. Adv Med Sci 2006; 51: 119-22.

25. Jiskra J, Antosová M, Límanová Z, Telicka Z, Lacinová Z. The relationship between thyroid function, serum monokine induced by interferon gamma and soluble interleukin-2 receptor in thyroid autoimmune diseases. Clin Exp Immunol 2009; 156: 211-6.

26. Pearce SHS. Spontaneous reporting of adverse reactions to carbimazole and propylthiouracil in the UK. Clin Endocrinol 2004; 61: 589-94.

27. Rivkees SA. Pediatric Graves' disease: controversies in management. Horm Res Paediatr 2010; 74: 305-11.

28. Cooper DS. Antithyroid drugs for the treatment of hyperthyroidism caused by Graves' disease. Endocrinol Metab Clin North Am 1998; 27: 225-47.

29. Molnár I. The balance shift in Th1/Th2 related IL-12/IL-5 cytokines in Graves' disease during methimazole therapy. Autoimmunity 2007; 40: 31-7.

30. Crescioli C, Cosmi L, Borgogni E, et al. Methimazole inhibits CXC chemokine ligand 10 secretion in human thyrocytes. J Endocrinol 2007; 195: 145-55.

31. Antonelli A, Rotondi M, Fallahi $P$, et al. Increase of interferon-gamma-inducible CXC chemokine CXCL10 serum levels in patients with active Graves' disease, and modulation by methimazole therapy. Clin Endocrinol 2006; 64: 189-95

32. Mitsiades N, Poulaki V, Tseleni-Balafouta S, Chrousos GP, Koutras DA. Fas ligand expression in thyroid follicular cells from patients with thionamide-treated Graves' disease. Thyroid 2000; 10: 527-32.

33. Hara H, Morita Y, Sato R, Ban Y. Circulating nuclear matrix protein in Graves' disease. Endocr J 2002; 49: 343-7.

34. Cooper DS. The side effects of antithyroid drugs. Endocrinologist 1999; 9: 457-76.

35. Williams KV, Natak S, Becker D, Reyes J, Burmeister LA. Fifty years of experience with propylthiouracil-associated hepatotoxicity: what have we learned? I Clin Endocrinol Metab 1997; 82: 1727-33.
36. Wenisch C, Myskiw D, Gessl A, Graninger W. Circulating selectins, intercellular adhesion molecule-1, and vascular cell adhesion molecule-1 in hyperthyroidism. J Clin Endocrinol Metab 1995; 80: 2122.

37. Oren R, Maaravi Y, Karmeli F, et al. Anti-thyroid drugs decrease mucosal damage in a rat model of experimental colitis. Aliment Pharmacol Ther 1997; 11: 341.

38. Dagia NM, Harii N, Meli AE. Phenyl methimazole inhibits TNF-alpha-induced VCAM-1 expression in an IFN regulatory factor-1-dependent manner and reduces monocytic cell adhesion to endothelial cells. J Immunol 2004; 173: 2041-9. 